\title{
The Versatile Functions of ATM Kinase
}

\author{
Rebecca J. Boohaker ${ }^{1}$, Bo Xu ${ }^{1,2}$
}

\begin{abstract}
Ataxia-telangiectasia mutated (ATM) kinase, the mutation of which causes the autosomal recessive disease ataxia-telangiectasia, plays an essential role in the maintenance of genome stability. Extensive studies have revealed that activated ATM signals to a massive list of proteins to facilitate cell cycle checkpoints, DNA repair, and many other aspects of physiological responses in the event of DNA double-strand breaks. ATM also plays functional roles beyond the well-characterized DNA damage response (DDR). In this review article, we discuss the recent findings on the molecular mechanisms of ATM in DDR, the mitotic spindle checkpoint, as well as hyperactive ATM signaling in cancer invasion and metastasis. (Biomed J 2014;37:3-9)
\end{abstract}

\section{Key words: ataxia-telangiectasia mutated, genome stability, metastasis, mitosis, Snail, spindle checkpoint}

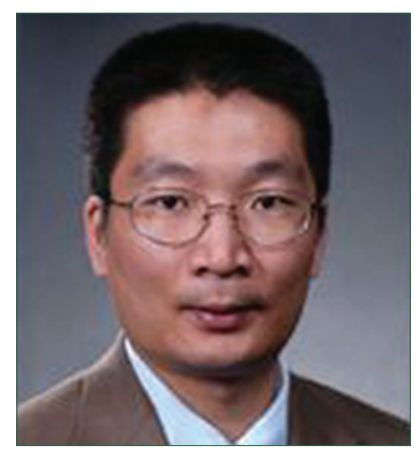

Dr. Bo Xu
$\mathrm{G}$ enetic diseases with cancer predisposition phenotypes provide insights into essential roles of the involved genes and their products in the maintenance of genome stability, as genome instability is one of the hallmarks of cancer. ${ }^{[1]}$ Ataxia-telangiectasia (A-T), a rare autosomal recessive disorder, is such an example. A-T is caused by mutations in the ataxia-telangiectasia mutated (ATM) gene, located on human chromosome 11q22.3. ${ }^{[2]}$ Depending on the extent of the mutation, the resultant loss of ATM protein expression or function can lead to pleiotropic clinical phenotypes, including a characteristic lack of coordination in limbs due to progressive neurodegeneration, predisposition to hematological malignancies (typically leukemia and lymphoma), immunodeficiency, as well as hypersensitivity to ionizing irradiation. ${ }^{[3]}$ The classical presentation of A-T is the result of two truncation mutations in ATM, subsequently leading to a loss of function in the ATM protein, with a less severe form of A-T that is usually associated with missense mutations or leaky splice sites within the ATM gene. This is typically attributed to defects on both alleles resulting in compound heterozygosity for a truncating mutation. The resulting translated ATM protein is not stable and, therefore, not functional. This type of loss of function is the main contributor to the radiosensitive phenotype in the patients.
Encoded by ATM, the ATM protein is a serine/ threonine kinase, and one of six members of the phosphatidylinositol-3 kinase related kinases (PIKKs). This protein family, which includes molecular hub proteins ATM and RAD-3 related (ATR), DNA protein kinase catalytic subunit (DNA-PKcs), mammalian target of rapamycin (mTOR), transformation/transcription domain-associated protein (TRRAP), and serine/threonine-protein kinase SMG1 (SMG-1), shares four conserved domains. ${ }^{[4]}$ These domains are unique to the PIKK family and include the FRAP-ATM-TRRAP (FAT) domain, the kinase domain (KD), the PIKK regulatory domain (PRD), and the FAT-C-terminal (FATC) domain. ${ }^{[5]}$ ATM itself is a $350 \mathrm{kDa}$ protein with 3056 amino acids. The enzymatic activity of ATM is stimulated in response to DNA damage, and the activation processes include a dimer to monomer dissociation and recruitment to the damage site. ${ }^{[6]}$ Several autophosphorylation events happen after DNA damage that might be essential for the dissociation process. ${ }^{[6,7]}$ The recruitment of ATM is partially dependent on the assembly of the MRN complex, comprising Mre11, DNA repair protein RAD50 (Rad50), and nibrin (NBS1), at the lesion. ${ }^{[8-11]}$ In this process, an interacting protein ATM interacting protein (ATMIN) is involved in the presence of changes in the chromatin structure. ${ }^{[12]}$ Activation of ATM is also dependent

From the ${ }^{1}$ Department of Oncology, Drug Discovery Division, Southern Research Institute, Birmingham, AL, USA; ${ }^{2}$ Cancer Cell Biology Program, Comprehensive Cancer Center, University of Alabama at Birmingham, Birmingham, AL, USA

Received: Jun. 27, 2013; Accepted: Sep. 27, 2013

Correspondence to: Dr. Bo Xu, Department of Oncology, Drug Discovery Division, Southern Research Institute, USA. $20009^{\text {th }}$ Ave South, Birmingham, AL 35205, USA. Tel: 205-581-2845; Fax: 205-581-2097; E-mail: xu@ sri.org

DOI: $10.4103 / 2319-4170.125655$ 
on mediator of DNA-damage checkpoint 1 (MDC1), which is recruited to the DNA damage site along with its interaction of gamma histone 2AX $(\gamma-\mathrm{H} 2 \mathrm{AX}) .{ }^{[13-15]}$ Other components of ATM activation pathways involve apoptosis, caspase activation inhibitor (AVEN), forkhead box O3 (FOXO3), $\mathrm{K}$ (lysine) acetyltransferase 8 (KAT8), high mobility group nucleosome binding domain 1 (HMGN1), ring finger protein 8, E3 ubiquitin protein ligase (RNF8), and checkpoint with forkhead and ring finger domains (CHFR). ${ }^{[16-20]}$ Activated ATM then sends signals to downstream targets to initiate an optimal DNA damage response (DDR). ${ }^{[21]}$ Elements involved in turning off the activated ATM when the optimal response is completed include wild-type p53-induced phosphatase 1 (WIP1), a type $2 \mathrm{C}$ protein phosphatase. ${ }^{[22]} \mathrm{In}$ addition to the protein-protein interaction and posttranslational modification involved in ATM activation during the DDR, ATM expression itself can be negatively regulated by micro-RNA (MiR)-421, MiR-18a, and 106a. ${ }^{[23-25]}$

Mouse models demonstrating ATM deficiencies have yielded useful information on the far-reaching activity of the kinase and its role in disease progression. Genetic knock-out of ATM recapitulates most of the clinical phenotypes except the neurological dysfunction. ${ }^{[26,27]}$ However, knock-in models with ATM point mutations on critical sites of ATM autophosphorylation failed to yield the expected phenotypes, ${ }^{[28]}$ suggesting mutations of known autophosphorylation sites do not have direct effects on the activation. Rather, this indicates that autophosphorylation events are a consequence of activation due to recruitment to damaged sites. Recent studies have shown an embryonic lethality conveyed by expression of a kinase-dead ATM. ${ }^{[29,30]}$ The observation that total protein deletion alone is not as detrimental as kinase inactivity is indicative of an underlying compensatory mechanism that is not engaged when ATM is present but inactive.

In addition to the well-characterized DDR, ATM activation can be observed in response to stresses like hypoxia and hyperthermia. ${ }^{[1,32]}$ Evidence on the cytoplasmic fraction of ATM $^{[33-36]}$ indicates a role of ATM in response to oxidative stress. ${ }^{[3]}$ In addition, ATM appears to be required for destruction of abnormal mitochondria, supporting a role of ATM in autophagy ${ }^{[37]}$ The scope of the ATM-mediated signaling pathways, far from being limited to a response to DNA damage, affects pathways in many facets of cellular function from gene expression to development. In this review, we discuss the function of ATM in cell cycle checkpoints, mitosis, and a potential role of hyperactivated ATM in promoting metastasis.

\section{ATM and DNA damage induced cell cycle checkpoints}

DDR pathways are complex and overlapping, mounting a multi-tiered response to DNA lesions in an effort to maintain genomic integrity. ${ }^{[38]}$ The activity of the DDR can engage pathways that dictate the life or death of a cell, convey either sensitivity or resistance to cancer therapeutics, or be a driver in tumor progression and metastasis. Cell cycle checkpoints, one of the well-documented DDR mechanisms, exist at each phase of the cell cycle to provide an opportunity for the cell to inspect and monitor the repair of DNA lesions. ${ }^{[39]}$ The versatility of the kinase activity of ATM allows for the protein to affect numerous downstream targets and signaling cascades ${ }^{[40]}$ In this manner, the ATM-driven DDR acts as a de facto regulator of cell cycle checkpoints [Figure 1].

In the event of DNA damage, entering S-phase will be slowed down with an accumulation of G1 phase cells, in order to prevent replication of damaged DNA. Direct targets of ATM in activating the G1/S checkpoint include tumor protein 53 (p53), E3 ubiquitin-protein ligase COP1 (COP1), checkpoint kinase 2 (Chk2), p53 E3 ubiquitin protein ligase homolog 2 (MDM2), Mdm4 p53 binding protein homolog (MDMX), and Rad9. ${ }^{[1]}$ For example, ATM phosphorylation of the tumor suppressor, $\mathrm{p} 53,{ }^{[42,43]}$ as well as its counterpart, MDM2, ${ }^{[44,45]}$ are required for activation of p53 in the presence of DNA damage. The p53-MDM2 complex is essential in inhibiting the activity of p53, and in the absence of the regulation provided to MDM2, $\mathrm{p} 21^{\mathrm{Cip} 1}$ is transcriptionally upregulated by $\mathrm{p} 53$. Further, ATM-mediated COP1 and MDMX phosphorylation results in polyubiquitination and proteasomal degradation of the proteins. ${ }^{[46,47]}$ These series of events result in an inhibition of cyclin dependent kinases (CDKs) 4, 6, and 2, and a stall in the G1/S transition. ${ }^{[48]}$

The intra-S-phase checkpoint, which directly represents the inhibition of DNA synthesis when S-phase cells are experiencing DNA damage, is mediated by ATM through regulating a number of downstream targets, including breast

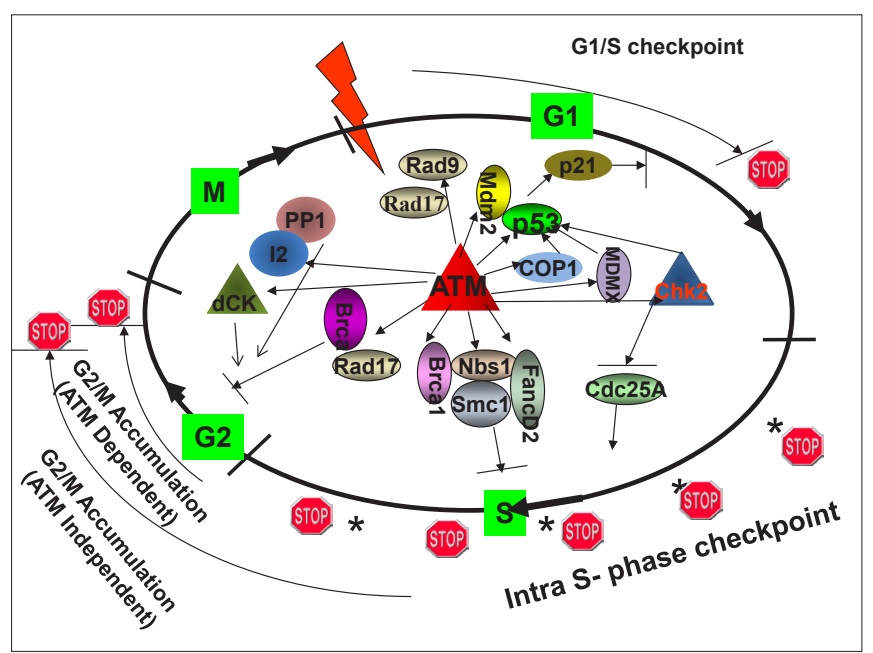

Figure 1: ATM-mediated phosphorylation of downstream targets is required for activation of the DNA damage induced cell cycle checkpoints. 
cancer 1, early onset (BRCA1), NBS1, structural maintenance of chromosomes 1 (SMC1), and Fanconi anemia complementation group D2 (FANCD2) ${ }^{[49]}$ However, it is still less clear how these post-translational modification events control inhibition of the replicon initiation and elongation processes after DNA damage. As a contrast, ATM-mediated Chk2 phosphorylation/activation results in phosphorylation of the phosphatase cell division cycle (Cdc) $25 \mathrm{~A}$, which inhibits loading of $\mathrm{Cdc} 45$ onto the replication origins required for replication initiation. ${ }^{[50]}$ Another potential target for ATM in regulating the intra-S-phase checkpoint is the Cdc7-DBF4-type zinc finger containing protein (DBF4) complex, which is required for replicon initiation. ${ }^{[51]}$ DBF4 is shown to be a substrate of ATM in the proteomic study, ${ }^{[40]}$ although the detailed mechanism remains unclear.

Cell cycle entry into mitosis from the $\mathrm{G} 2$ phase must be critically monitored to ensure that chromosome segregation is not initiated before DNA damage lesions are appropriately repaired. Using flow cytometry-based cell cycle analysis, two molecularly distinct G2/M checkpoints can be observed, one ATM dependent and the other ATM independent. ${ }^{[52]}$ The ATM-dependent G2/M checkpoint happens immediately after DNA damage and represents a response of irradiated $\mathrm{G} 2$ cells. The ATM-independent $\mathrm{G} 2$ accumulation represents a response of cells when they are in S-phase or even G1 phase at the time of DNA damage. An S-phase checkpoint defect might result in cells accumulated in G2 for a prolonged period. The prolonged G2 accumulation represents an engagement of a DNA replication checkpoint. This abnormal G2 accumulation has been observed in cell lines with deficient ATM, NBS1, and Brca1. Substrates of ATM in regulating the early $\mathrm{G} 2 / \mathrm{M}$ checkpoint include Brca1, ${ }^{[53,54]}$ Chk2, ${ }^{[5,56]}$ deoxycytidine kinase (dCK), ${ }^{[57]} \operatorname{Rad} 17,{ }^{[58,59]}$ and phosphatase inhibitor 2 (I-2). ${ }^{[60]}$ For example, ATM-mediated Chk2 activation results in inhibition of the $\mathrm{Cdc} 25$ family members and activation of the G2/M checkpoint. ${ }^{[61]}$ ATM also regulates protein phosphatase 1 (PP1) activity by phosphorylating inhibitor 2 (I-2), an inhibitory subunit of the PP1 complex. This phosphorylation leads to dissociation of the PP1 complex and activation of PP1, which in turn affects the balance of histone $\mathrm{H} 3$ serine 10 phosphorylation, resulting in immediate $\mathrm{G} 2$ arrest. ${ }^{[60]}$ Recent data from our lab also showed that dCK is a downstream target of ATM in the G2/M checkpoint pathway. Phosphorylated and activated dCK interacts with cyclin dependent kinase 1 (CDK1), and an enhanced interaction results in inhibition of CDK1. ${ }^{[57]}$

\section{$A T M$ in mitosis}

Key to the successful completion of the cell cycle is the segregation of chromosomes during the metaphase/ anaphase transition within mitosis. Improper segregation of chromosomes leads to aneuploidy, frequently observed in cancer. ${ }^{[1]}$ The major driver of proper segregation occurs during metaphase when the mitotic spindles project from centrioles at the polar ends of a cell ready to divide to connect to the chromosomes aligned at the metaphase plate. The regulator of the transition from metaphase to anaphase as well as chromosomal segregation is the spindle assembly checkpoint (SAC) ${ }^{[62]}$ The SAC involves a conserved network of mitotic arrest deficient (Mad) and budding uninhibited by benzimidazoles homolog (Bub) proteins, and acts as a surveillance system to monitor kinetochore-microtubule interactions during chromosome alignment on the mitotic spindle. ${ }^{[63,64]}$

While the activity of ATM in the DDR is, and has been, the focus of a majority of studies to date, the role ATM in the proper execution of mitosis is emerging. For example, ATM deficiency in human, mouse, and cellular models correlate with aneuploidy due to dysregulation within the metaphase/ anaphase transition. ${ }^{[65-68]}$ Furthermore, a measurable and marked increase in ATM kinase activity during mitosis has been observed in the absence of DNA damage. ${ }^{[69]}$ The manifestation of these mitotic timing defects may be more prevalent in the presence of ionizing radiation, as the hypersensitivity to radiotherapy observed in ATM-deficient cells may be indicative of the compounding effect of an ineffective DDR coupled with a suboptimal mitotic checkpoint. Thus, a regulatory role of ATM in mitosis that is outside that of the classical DNA damage response merits closer examination.

Mitotic activation of ATM is mediated by Aurora B-mediated phosphorylation, specifically at serine 1403 [Figure 2] ${ }^{[69]}$ We have also observed interactions of ATM and Aurora B in mitosis (unpublished data), although it is less clear whether this interaction promotes phosphorylation or vice versa. The mechanism of ATM activation in mitosis is clearly distinct from ATM activation in the DDR. For example, when ATM is activated in response to double-stranded breaks (DSB), Aurora B is inhibited indirectly by the kinase (through ATM-mediated PP1 activation); but in mitosis, Aurora B is activated during mitotic progression and ATM becomes its target. ${ }^{[60,69]}$ This allows for differential functioning of ATM in the regulation of mitotic progression, and also provides a possible molecular switch between the DDR and the proper execution of mitosis.

Active ATM participates in the mitotic process by targeting a critical component of the SAC, a serine/threonine kinase, Bub1. Phosphorylation of Bub1 at serine 314 by ATM serves as an activator of Bub1 in mitosis. ${ }^{[0]}$ Bub1 activation results in the phosphorylation of $\mathrm{Cdc} 20$, which allows the mitotic checkpoint complex (MCC) to inhibit anaphase promoting complex or cyclosome (APC/C), thereby regulating mitotic progression into anaphase. ${ }^{[1]}$ Dysregulation of this checkpoint could either result in premature entry into anaphase or in merotelic attachment in which 
the kinetochores are attached but at least one is attached to the microtubules from both spindle poles. ${ }^{[2]}$ In either case, the resultant segregation in anaphase is unequal and likely to result in aneuploidy.

A comprehensive picture of ATM-mediated SAC regulatory network is emerging. Downstream targets are likely to include more mitotic checkpoint proteins in addition to Bub1. For instance, of the constituent proteins in the SAC, recent studies in our lab have shown that mitotic arrest deficient 1 (Mad1) can be phosphorylated by ATM at Ser 214 in mitosis (manuscript under revision). This phosphorylation promotes the complex of Mad1 with Mad2 at an improperly attached kinetochore. This is a key regulatory step as Mad2, along with Cdc20, Mad3 [MAD3/BUB1-related protein kinase (BubR1)], and Bub3 form MCC. ${ }^{[73]}$ This complex binds to the APC/C, inactivating it and halting the cell cycle until all the kinetochore attachments to chromosomes are complete. The role of ATM in the formation and regulation of this complex becomes critical when examining how the Mad proteins exist in a balance to modulate the flow of $\mathrm{Cdc} 20$ through the pathway.

\section{ATM hyperactivation and tumor metastasis}

DDR mechanisms are considered as an antitumor barrier during early tumorigenesis. ${ }^{[7-76]}$ However, there is growing evidence that DDR elements might play a role in

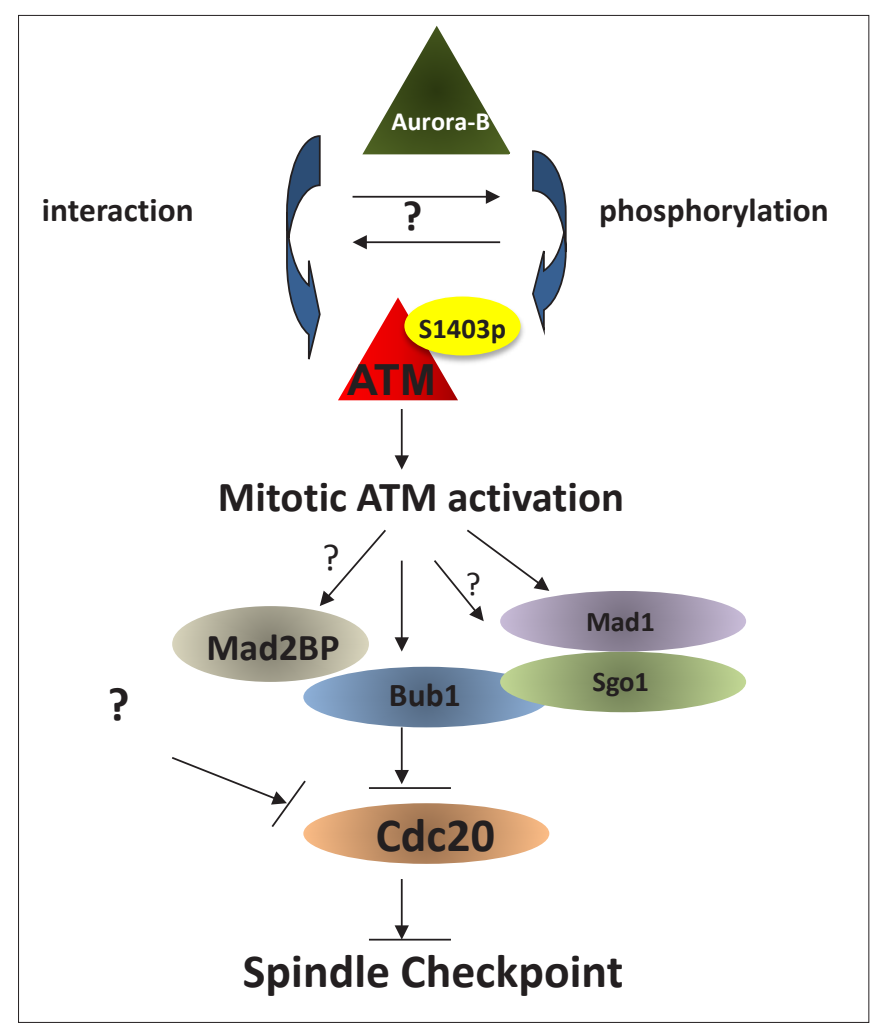

Figure 2: The schematic model of ATM activation in mitosis and its role in the spindle checkpoint. tumor progression, such as invasion and metastasis. For example, NBS1 is over-expressed in advanced head and neck squamous cell carcinoma (HNSCC), and in vitro and in vivo evidence revealed that over-expressing NBS1 up-regulated Snail, a transcriptional repressor associated with tumor invasion and metastasis, and its downstream target, matrix metalloproteinase-2, in HNSCC. ${ }^{[7]]}$

Key to tumor progression is the epithelial-mesenchymal transition (EMT), an early step of tumor metastasis. ${ }^{[78]}$ One of the more notable characteristics of EMT is the loss of expression of E-cadherin, a surface protein that is responsible for cell-to-cell adhesion. ${ }^{[79]}$ This expression is regulated by Snail, which when active, binds to the E-boxes of E-cadherin, inhibiting expression at the plasma membrane. ${ }^{[80]}$ Our recent data found that surprisingly, ATM may directly contribute to EMT through activation of the ATM-Snail pathway. ATM is found to be hyperactive in late stage breast cancer and this hyperactivity correlates with Snail expression. Indeed, ATM can stabilize Snail via phosphorylation at serine $100{ }^{[81]}$ This phosphorylation allows for binding of heat shock protein (HSP) 90 to Snail, stabilizing it, and allowing Snail to down-regulate E-cadherin expression. Implication of the ATM-Snail interaction in the promotion of tumor formation can be seen with the expression of constitutively active Snail expression resulting in increased invasion [Figure 3]. ${ }^{[81]}$ With maintenance of genomic stability playing such an integral role in the survival of a cell, it is conceivable that an optimal DDR (such as activation of the ATM-Snail pathway) promotes survival during tumor progression. This is supported by our recent data showing that hyperactivation of ATM phosphorylation of Snail decreases sensitivity to radiation treatment. ${ }^{[82]}$

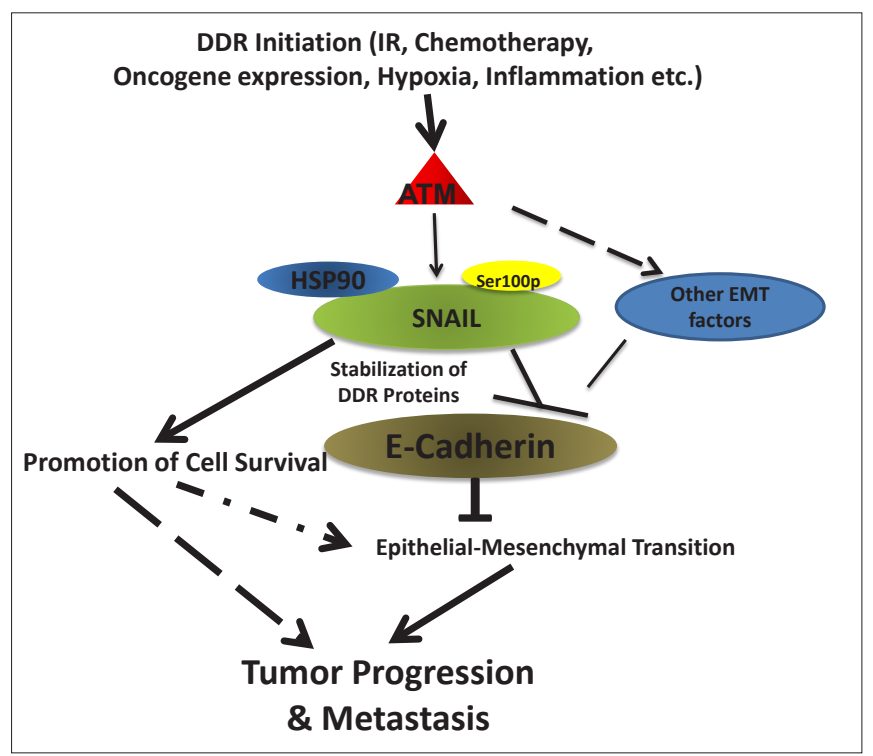

Figure 3: Potential roles of ATM hyperactivation in tumor progression and metastasis. 
It is still unclear regarding the mechanisms driving persistent activation of ATM at late stages of tumor progression. It is likely that tumor microenvironment might play a significant role in the process. Chronic hypoxia, for example, is one of the conditions in advanced tumors in favor of activating ATM. ${ }^{[31]}$ Additionally, a recent study found that inflammation within the tumor microenvironment contributes to a persistent DDR, as measured by ATM S1981 phosphorylation not only within the tumor, but also within non-malignant tissue in the environment adjacent to the malignancy. ${ }^{[83]}$ As EMT is regulated by multiple transcription repressors of E-cadherin, it is likely that the other components of EMT such as the Snail/Slug family, Twist, zinc finger E-box binding homeobox 1 (ZEB1), Smad interacting protein 1 (SIP1), and E12/E47 are components of the ATM pathway.

\section{Conclusion}

ATM is a central controller of genomic stability, which requires the coordination of a number of different overlapping processes. The cell cycle's tight monitoring of DNA replication fidelity and recruitment of repair proteins in the presence of DNA lesions are the key barriers in tumorigenesis. Within mitosis, proper chromosomal segregation is paramount in successful cell division. The DDR pathways that are elicited as a result of ATM activation serve as tumor suppressive responses allowing for DNA repair before perpetuating the error through the cycle and onto the newly divided cells. Within mitosis, ATM activation promotes initiation of the SAC, allowing for the metaphase-anaphase transition to be monitored. Perpetuated activity of ATM, however, can be detrimental in the context of tumor progression. The increased activity of ATM can convey protection against DNA damage via overactivation of the DDR. In particular, ATM promotes metastasis through the stabilization of Snail and the subsequent loss of E-cadherin expression. The seemingly far-reaching activity of ATM underscores the need to examine its increasingly complex role in tumor suppression on the one hand and its tumor promotion on the other. A fundamental understanding of the mechanism by which ATM activity can exert its effect on such variety of pathways is needed. The broad reach of ATM's activity suggests that there may be a number of physiological manifestations that can be attributed to functions of ATM that are yet to be described. ATM appears to play a role in a number of integral intracellular pathways, and can exercise its activity on many downstream targets. As new functions of ATM emerge, the greatest benefit of thorough examination of the role of ATM in the maintenance of genetic and chromosomal stability is the insight gained into the proximal contributors of the various pathways, thereby identifying novel drug targets and biomarkers for screening.

\section{Acknowledgment}

This work was supported by the United States National Institutes of Health (NIH) grants R01CA133093 and R01ES016354.

\section{REFERENCES}

1. Hanahan D, Weinberg RA. Hallmarks of cancer: The next generation. Cell 2011;144:646-74.

2. Lavin MF. Ataxia-telangiectasia: From a rare disorder to a paradigm for cell signalling and cancer. Nat Rev Mol Cell Biol 2008;9:759-69.

3. Shiloh Y, Ziv Y. The ATM protein kinase: Regulating the cellular response to genotoxic stress, and more. Nat Rev Mol Cell Biol 2013;14:197-210.

4. Kastan MB, Lim DS. The many substrates and functions of ATM. Nat Rev Mol Cell Biol 2000;1:179-86.

5. Lempiainen H, Halazonetis TD. Emerging common themes in regulation of PIKKs and PI3Ks. EMBO J 2009;28:3067-73.

6. Bakkenist CJ, Kastan MB. DNA damage activates ATM through intermolecular autophosphorylation and dimer dissociation. Nature 2003;421:499-506.

7. Kozlov SV, Graham ME, Peng C, Chen P, Robinson PJ, Lavin MF Involvement of novel autophosphorylation sites in ATM activation. EMBO J 2006;25:3504-14.

8. Uziel T, Lerenthal Y, Moyal L, Andegeko Y, Mittelman L, Shiloh Y. Requirement of the MRN complex for ATM activation by DNA damage. EMBO J 2003;22:5612-21.

9. Lee JH, Paull TT. ATM activation by DNA double-strand breaks through the Mre11-Rad50-Nbs1 complex. Science 2005;308:551-4.

10. Lee JH, Paull TT. Direct activation of the ATM protein kinase by the Mre11/Rad50/Nbs1 complex. Science 2004;304:93-6.

11. Lee JH, Paull TT. Activation and regulation of ATM kinase activity in response to DNA double-strand breaks. Oncogene 2007;26:7741-8.

12. Kanu N, Behrens A. ATMIN defines an NBS1-independent pathway of ATM signalling. EMBO J 2007;26:2933-41.

13. Mochan TA, Venere M, DiTullio RA Jr, Halazonetis TD. 53BP1 and NFBD1/MDC1-Nbs1 function in parallel interacting pathways activating ataxia-telangiectasia mutated (ATM) in response to DNA damage. Cancer Res 2003;63:8586-91.

14. Goldberg M, Stucki M, Falck J, D’Amours D, Rahman D, Pappin D, et al. MDC1 is required for the intra-S-phase DNA damage checkpoint. Nature 2003;421:952-6.

15. Stucki M, Clapperton JA, Mohammad D, Yaffe MB, Smerdon SJ, Jackson SP. MDC1 directly binds phosphorylated histone H2AX to regulate cellular responses to DNA double-strand breaks. Cell 2005;123:1213-26.

16. Guo JY, Yamada A, Kajino T, Wu JQ, Tang W, Freel CD, et al. Aven-dependent activation of ATM following DNA damage. Curr Biol 2008;18:933-42.

17. Tsai WB, Chung YM, Takahashi Y, Xu Z, Hu MC. Functional interaction between FOXO3 and ATM regulates DNA damage response. Nat Cell Biol 2008;10:460-7.

18. Wu J, Chen Y, Lu LY, Wu Y, Paulsen MT, Ljungman M, et al. Chfr 
and RNF8 synergistically regulate ATM activation. Nat Struct Mol Biol 2011;18:761-8.

19. Kim YC, Gerlitz G, Furusawa T, Catez F, Nussenzweig A, Oh KS, et al. Activation of ATM depends on chromatin interactions occurring before induction of DNA damage. Nat Cell Biol 2009;11:92-6.

20. Gupta A, Sharma GG, Young CS, Agarwal M, Smith ER, Paull TT, et al. Involvement of human MOF in ATM function. Mol Cell Biol 2005;25:5292-305.

21. Kastan MB, Lim DS, Kim ST, Xu B, Canman C. Multiple signaling pathways involving ATM. Cold Spring Harb Symp Quant Biol 2000;65:521-6.

22. Shreeram S, Demidov ON, Hee WK, Yamaguchi H, Onishi N, Kek C, et al. Wip1 phosphatase modulates ATM-dependent signaling pathways. Mol Cell 2006;23:757-64.

23. $\mathrm{Hu} \mathrm{H}, \mathrm{Du}$ L, Nagabayashi G, Seeger RC, Gatti RA. ATM is down-regulated by N-Myc-regulated microRNA-421. Proc Natl Acad Sci U S A 2010;107:1506-11.

24. Song L, Lin C, Wu Z, Gong H, Zeng Y, Wu J, et al. miR-18a impairs DNA damage response through downregulation of ataxia telangiectasia mutated (ATM) kinase. PLoS One 2011;6:e25454.

25. Guo X, Yang C, Qian X, Lei T, Li Y, Shen H, et al. Estrogen Receptor alpha Regulates ATM Expression through miRNAs in Breast Cancer. Clin Cancer Res 2013;19:4994-5002.

26. Barlow C, Hirotsune S, Paylor R, Liyanage M, Eckhaus M, Collins F, et al. Atm-deficient mice: A paradigm of ataxia telangiectasia. Cell 1996;86:159-71.

27. Xu Y, Ashley T, Brainerd EE, Bronson RT, Meyn MS, Baltimore D. Targeted disruption of ATM leads to growth retardation, chromosomal fragmentation during meiosis, immune defects, and thymic lymphoma. Genes Dev 1996;10:2411-22.

28. Daniel JA, Pellegrini M, Lee JH, Paull TT, Feigenbaum L, Nussenzweig A. Multiple autophosphorylation sites are dispensable for murine ATM activation in vivo. J Cell Biol 2008;183:777-83.

29. Daniel JA, Pellegrini M, Lee BS, Guo Z, Filsuf D, Belkina NV, et al. Loss of ATM kinase activity leads to embryonic lethality in mice. J Cell Biol 2012;198:295-304.

30. Yamamoto K, Wang Y, Jiang W, Liu X, Dubois RL, Lin CS, et al. Kinase-dead ATM protein causes genomic instability and early embryonic lethality in mice. J Cell Biol 2012;198:305-13.

31. Hammond EM, Giaccia AJ. The role of ATM and ATR in the cellular response to hypoxia and re-oxygenation. DNA Repair (Amst) $2004 ; 3: 1117-22$

32. Hunt CR, Pandita RK, Laszlo A, Higashikubo R, Agarwal M, Kitamura $\mathrm{T}$, et al. Hyperthermia activates a subset of ataxia-telangiectasia mutated effectors independent of DNA strand breaks and heat shock protein 70 status. Cancer Res 2007;67:3010-7.

33. Watters D, Kedar P, Spring K, Bjorkman J, Chen P, Gatei M, et al. Localization of a portion of extranuclear ATM to peroxisomes. J Biol Chem 1999;274:34277-82.

34. Li J, Han YR, Plummer MR, Herrup K. Cytoplasmic ATM in neurons modulates synaptic function. Curr Biol 2009;19:2091-6.

35. Lim DS, Kirsch DG, Canman CE, Ahn JH, Ziv Y, Newman LS, et al. ATM binds to beta-adaptin in cytoplasmic vesicles. Proc Natl Acad Sci U S A 1998;95:10146-51.

36. Yang DQ, Kastan MB. Participation of ATM in insulin signalling through phosphorylation of eIF-4E-binding protein 1. Nat Cell Biol 2000;2:893-8.

37. Valentin-Vega YA, Kastan MB. A new role for ATM: Regulating mitochondrial function and mitophagy. Autophagy 2012;8:840-1.

38. Jackson SP, Bartek J. The DNA-damage response in human biology and disease. Nature 2009;461:1071-8.

39. Kastan MB, Bartek J. Cell-cycle checkpoints and cancer. Nature 2004;432:316-23.

40. Matsuoka S, Ballif BA, Smogorzewska A, McDonald ER $3^{\text {rd }}$, Hurov KE, Luo J, et al. ATM and ATR substrate analysis reveals extensive protein networks responsive to DNA damage. Science 2007;316:1160-6.

41. Shiloh Y. ATM and related protein kinases: Safeguarding genome integrity. Nat Rev Cancer 2003;3:155-68.

42. Canman CE, Lim DS, Cimprich KA, Taya Y, Tamai K, Sakaguchi K, et al. Activation of the ATM kinase by ionizing radiation and phosphorylation of p53. Science 1998;281:1677-9.

43. Banin S, Moyal L, Shieh S, Taya Y, Anderson CW, Chessa L, et al. Enhanced phosphorylation of p53 by ATM in response to DNA damage. Science 1998;281:1674-7.

44. Maya R, Balass M, Kim ST, Shkedy D, Leal JF, Shifman O, et al. ATM-dependent phosphorylation of Mdm2 on serine 395: Role in p53 activation by DNA damage. Genes Dev 2001;15:1067-77.

45. Gannon HS, Woda BA, Jones SN. ATM phosphorylation of Mdm2 Ser394 regulates the amplitude and duration of the DNA damage response in mice. Cancer Cell 2012;21:668-79.

46. Dornan D, Shimizu H, Mah A, Dudhela T, Eby M, O'Rourke K, et al. ATM engages autodegradation of the E3 ubiquitin ligase COP1 after DNA damage. Science 2006;313:1122-6.

47. Chen L, Gilkes DM, Pan Y, Lane WS, Chen J. ATM and Chk2-dependent phosphorylation of MDMX contribute to p53 activation after DNA damage. EMBO J 2005;24:3411-22.

48. Batchelor E, Mock CS, Bhan I, Loewer A, Lahav G. Recurrent initiation: A mechanism for triggering p 53 pulses in response to DNA damage. Mol Cell 2008;30:277-89.

49. Kastan MB. DNA damage responses: Mechanisms and roles in human disease: 2007 G.H.A. Clowes Memorial Award Lecture. Mol Cancer Res 2008;6:517-24.

50. Falck J, Mailand N, Syljuasen RG, Bartek J, Lukas J. The ATM-Chk2-Cdc25A checkpoint pathway guards against radioresistant DNA synthesis. Nature 2001;410:842-7.

51. Woo RA, Poon RY. Cyclin-dependent kinases and S phase control in mammalian cells. Cell Cycle 2003;2:316-24.

52. Xu B, Kim ST, Lim DS, Kastan MB. Two molecularly distinct $\mathrm{G}$ (2)/M checkpoints are induced by ionizing irradiation. Mol Cell Biol 2002;22:1049-59.

53. Xu B, Kim S, Kastan MB. Involvement of Brca1 in S-phase and $\mathrm{G}$ (2)-phase checkpoints after ionizing irradiation. Mol Cell Biol 2001;21:3445-50.

54. Xu B, O'Donnell AH, Kim ST, Kastan MB. Phosphorylation of serine 1387 in Brcal is specifically required for the Atm-mediated S-phase checkpoint after ionizing irradiation. Cancer Res 2002;62:4588-91.

55. Ahn JY, Schwarz JK, Piwnica-Worms H, Canman CE. Threonine 68 phosphorylation by ataxia telangiectasia mutated is required for 
efficient activation of $\mathrm{Chk} 2$ in response to ionizing radiation. Cancer Res 2000;60:5934-6.

56. Matsuoka S, Rotman G, Ogawa A, Shiloh Y, Tamai K, Elledge SJ. Ataxia telangiectasia-mutated phosphorylates Chk2 in vivo and in vitro. Proc Natl Acad Sci U S A 2000;97:10389-94.

57. Geng C, He B, Xu L, Barbieri CE, Eedunuri VK, Chew SA, et al. Prostate cancer-associated mutations in speckle-type $\mathrm{POZ}$ protein (SPOP) regulate steroid receptor coactivator 3 protein turnover. Proc Natl Acad Sci U S A 2013;110:6997-7002.

58. Bao S, Tibbetts RS, Brumbaugh KM, Fang Y, Richardson DA, Ali A, et al. ATR/ATM-mediated phosphorylation of human Rad17 is required for genotoxic stress responses. Nature 2001;411:969-74.

59. Garg R, Callens S, Lim DS, Canman CE, Kastan MB, Xu B. Chromatin association of rad17 is required for an ataxia telangiectasia and rad-related kinase-mediated S-phase checkpoint in response to low-dose ultraviolet radiation. Mol Cancer Res 2004;2:362-9.

60. Tang X, Hui ZG, Cui XL, Garg R, Kastan MB, Xu B. A novel ATM-dependent pathway regulates protein phosphatase 1 in response to DNA damage. Mol Cell Biol 2008;28:2559-66.

61. Matsuoka S, Huang M, Elledge SJ. Linkage of ATM to cell cycle regulation by the Chk2 protein kinase. Science 1998;282:1893-7.

62. Foley EA, Kapoor TM. Microtubule attachment and spindle assembly checkpoint signalling at the kinetochore. Nat Rev Mol Cell Biol 2013;14:25-37.

63. Musacchio A, Hardwick KG. The spindle checkpoint: Structural insights into dynamic signalling. Nat Rev Mol Cell Biol 2002;3:731-41.

64. May KM, Hardwick KG. The spindle checkpoint. J Cell Sci 2006;119:4139-42.

65. Shigeta T, Takagi M, Delia D, Chessa L, Iwata S, Kanke Y, et al. Defective control of apoptosis and mitotic spindle checkpoint in heterozygous carriers of ATM mutations. Cancer Res 1999;59:2602-7.

66. Takagi M, Delia D, Chessa L, Iwata S, Shigeta T, Kanke Y, et al. Defective control of apoptosis, radiosensitivity, and spindle checkpoint in ataxia telangiectasia. Cancer Res 1998;58:4923-9.

67. Shen KC, Heng H, Wang Y, Lu S, Liu G, Deng CX, et al. ATM and $\mathrm{p} 21$ cooperate to suppress aneuploidy and subsequent tumor development. Cancer Res 2005;65:8747-53.

68. Iourov IY, Vorsanova SG, Liehr T, Kolotii AD, Yurov YB. Increased chromosome instability dramatically disrupts neural genome integrity and mediates cerebellar degeneration in the ataxia-telangiectasia brain. Hum Mol Genet 2009;18:2656-69.

69. Yang C, Tang X, Guo X, Niikura Y, Kitagawa K, Cui K, et al. Aurora-B mediated ATM serine 1403 phosphorylation is required for mitotic ATM activation and the spindle checkpoint. Mol Cell 2011;44:597-608.

70. Yang $\mathrm{C}$, Wang $\mathrm{H}, \mathrm{Xu} \mathrm{Y}$, Brinkman KL, Ishiyama $\mathrm{H}$, Wong ST, et al. The kinetochore protein Bub1 participates in the DNA damage response. DNA Repair (Amst) 2012;11:185-91.

71. Morrow CJ, Tighe A, Johnson VL, Scott MI, Ditchfield C, Taylor SS. Bub1 and aurora B cooperate to maintain BubR1-mediated inhibition of APC/CCdc20. J Cell Sci 2005;118:3639-52.

72. Fu J, Bian M, Jiang Q, Zhang C. Roles of Aurora kinases in mitosis and tumorigenesis. Mol Cancer Res 2007;5:1-10.

73. Fang G, Yu H, Kirschner MW. Control of mitotic transitions by the anaphase-promoting complex. Philos Trans R Soc Lond B Biol Sci 1999;354:1583-90.

74. Bartkova J, Rezaei N, Liontos M, Karakaidos P, Kletsas D, Issaeva $\mathrm{N}$, et al. Oncogene-induced senescence is part of the tumorigenesis barrier imposed by DNA damage checkpoints. Nature 2006;444:633-7.

75. Bartkova J, Horejsi Z, Koed K, Kramer A, Tort F, Zieger K, et al. DNA damage response as a candidate anti-cancer barrier in early human tumorigenesis. Nature 2005;434:864-70.

76. Gorgoulis VG, Vassiliou LV, Karakaidos P, Zacharatos P, Kotsinas A, Liloglou T, et al. Activation of the DNA damage checkpoint and genomic instability in human precancerous lesions. Nature 2005;434:907-13.

77. Yang MH, Chang SY, Chiou SH, Liu CJ, Chi CW, Chen PM, et al. Overexpression of NBS1 induces epithelial-mesenchymal transition and co-expression of NBS1 and Snail predicts metastasis of head and neck cancer. Oncogene 2007;26:1459-67.

78. Thiery JP. Epithelial-mesenchymal transitions in tumour progression. Nat Rev Cancer 2002;2:442-54.

79. Huber MA, Kraut N, Beug H. Molecular requirements for epithelial-mesenchymal transition during tumor progression. Curr Opin Cell Biol 2005; 17:548-58.

80. Nieto MA. The snail superfamily of zinc-finger transcription factors. Nat Rev Mol Cell Biol 2002;3:155-66.

81. Sun M, Guo X, Qian X, Wang H, Yang C, Brinkman KL, et al. Activation of the ATM-Snail pathway promotes breast cancer metastasis. J Mol Cell Biol 2012;4:304-15.

82. Boohaker RJ, Cui X, Stackhouse M, Xu B. ATM-mediated Snail Serine 100 phosphorylation regulates cellular radiosensitivity. Radiother Oncol 2013;108:403-8.

83. He H, Tian D, Guo J, Liu M, Chen Z, Hamdy FC, et al. DNA damage response in peritumoral regions of oesophageal cancer microenvironment. Carcinogenesis 2013;34:139-45. 